\title{
Effect of Financial Resources on the Delivery of Devolved Services in Selected Counties in Kenya
}

\author{
Fauziya Brek Karama \\ PhD Student, Department of Entrepreneurship, Technology, Leadership and Management, College of Human \\ Resource Development, Jomo Kenyatta University of Agriculture and Technology \\ Dr. Julius Monzi Muia \\ State Department for Planning, Government of Kenya
}

\begin{abstract}
The aim of this paper was to ascertain the effect of financial resources on the delivery of devolved services in selected counties in Kenya. The study was anchored on Resource Based View Theory, employing a blended research design and positivism approach. Data was collected using structured and open-ended questionnaires from 384 employees that were randomly selected from eight counties. Results from regression analysis showed that financial resources had significant and positive effects on devolved service delivery. The study concludes that financial resources are significant drivers of projects in counties. It is however a delicate balance since financial resources may be in place but the mechanisms to deploy them may be non-existent. Therefore, it is important for county governments to provide both financial and organizational resources in order to achieve improved delivery of county services.
\end{abstract}

Keywords: County government, Delivery, Devolved Services, Financial Resources

DOI: $10.7176 / \mathrm{EJBM} / 11-18-17$

Publication date:June $30^{\text {th }} 2019$

\subsection{Introduction}

Devolution is a decentralization tool aimed at improving good governance and giving more weight to the voices of the masses while improving their economic performance. According to Cole (2012), devolved units are characterized by an increased degree of independence that contributes to an improvement in their capacity to provide more impactful changes and developments for their people. Additionally, World Bank (2013) opines that devolution came about out of the need to protect the rights of the weakest members of society particularly because of the social dynamics promoted by the caste system. As such, devolution sought to change the status quo and enhance the government's participation in the direct protection of the rights of all its citizens by improving the capacity of local government units to offer their citizens better services and faster attention and response.

Bigambo (2013) provides a useful summary of how devolution has progressed in Africa as follows: Ethiopia in 1994, Uganda in 1995, Nigeria in 1999, South Africa in 1996 and Kenya in 2013. Many countries across the African continent are increasingly turning towards devolution because of its benefits in unifying and accommodating diversity, improving essential services infrastructure and inspiring higher development while ensuring equally high levels of good governance (Kauzya 2007). Empowering the public in governance increases the effectiveness of development project processes through the synergies that come about from the diversity of ideas. In addition, their active involvement in project management processes increases their investment in the success of public projects and facilitates public oversight on account of the resulting better public understanding of the intricacies involved in implementation. As such, the dynamics of devolution often improve the sustainability of public projects because of the deliberate changes it makes to public governance and decision-making. Contributing to this debate, Pollitt and Bouckaert (2011) opine that by moving most decision-making powers closer to the people, devolution improves a country's capacity and ability to develop strategic knowledge and competencies that improve the availability, quality and reliability of service delivery. In addition, the increasing knowledge and experience further help to enhance the improvements of the structures and models put in place to ensure they suit the unique circumstances of the area of implementation in order to improve service delivery. This is summed up by Expo(2007) who observes that devolution in Africa ensures good governance and effective service delivery. For devolution to succeed in supporting devolved service delivery there must be adequate frameworks to regulate the relationship between the national government and the devolved units so that no roles and responsibilities are neglected.

In a study by the World Bank (2012), Kenya's devolution was found to be a set of ambitious programs, by international standards, whereby implementing the transition from a centralized system to devolved government at one go including an overhaul of all the national structures and systems was seen to pose a national challenge. A lot of expectations have been put on devolution where, among other things, it is seen as a game changer in development, governance and inclusion by many people in Kenya and indeed the East African region. This is partly evidenced by the increasing agitation for, and expectation of, quality services. However in Kenya, devolved 
services have faced challenges in implementation, according to World Bank (2015), with the major problems being the result of poor accountability frameworks that reduce transparency and public trust in the whole system. As a result, many disenfranchised groups find themselves faced with policies that they have very little control over with regard to how they are developed or implemented. Thus, this study aims to explore how financial resources affect devolution and its realization in devolved service delivery in Kenyan counties.

\subsection{Literature Review}

Literature abounds showing that financial resources are one of the pillars for effective service delivery. According to Ghatak (2013), the agenda for effective public service provision has to be adequately financed. This depends critically on the institutional structures as well as technological issues. Unless provision of resources is based on effective delivery mechanisms, resources will be wasted. Each county should have its own system of enforcement mechanisms. Moreover, unwritten rules are likely to hinder or support public service provision.

Stacey (2011) defines a resource as a stock or supply of money, materials, staff and other assets that can be drawn on by a person or organization in order to function effectively. Accessing and acquiring such resources by sub-national units is an important consideration because one of the tenets of decentralization is sharing of resources. In this regard, an assessment by the Commission on Implementation of the Constitution (CIC) Kenya (2014) revealed that during the first one-year of devolution, counties experienced disputes relating to boundaries, revenue collections and management of natural resources among others.

From an empirical perspective, the study by Tsofa (2017) on Kilifi County Government, one of the 47 counties in Kenya, provides useful insights. The study established that financial resources and human resources for health management functions, a devolved service, were rapidly transferred to counties before appropriate county-level structures and adequate capacity to undertake these functions were put in place. This led to disruptions in staff salary payments, political interference with management functions and confusion over health sector roles. In addition, there was also a lack of clarity over specific roles and responsibilities at county and national government, and of key players at each level. Subsequently, Kilifi County witnessed several health workers' strikes and mass resignations. Service delivery was further compromised on account of significant delays in procurement that led to long stock-outs of essential drugs in health facilities.

Upon examining five key functions of hospitals after devolution, Barasa (2017) reports that there was a substantial reduction in the autonomy of county hospitals. Some of this resulted in weakened hospital management and leadership, reduced community participation in hospital affairs, compromised quality of services, reduced motivation among hospital staff, non-alignment of county hospital priorities, staff insubordination, and compromised quality of care. Barasa reported that the negative effect on service delivery can be reversed by increasing the autonomy of county hospitals and developing county legislation to give hospitals greater control over resources and key management functions.

The above notwithstanding, contrasting findings were reported by Maina (2017) who sampled three counties (Nairobi, Kiambu and Kajiado) in Kenya to examine the role of public financial management practices on service delivery. The study findings were that budgeting and stakeholder participation practices and regulatory practices had a positive effect on service delivery in the selected counties. Another interesting finding was that revenue mobilization, spending practices, auditing and forensic accounting practices had an insignificant effect on service delivery. Three recommendations from the study are relevant for this paper. Firstly, in order to be more effective, counties should prepare plans and budgets with high levels of participation and ownership by the public. Secondly, spending above the budget estimates should be discouraged. Thirdly, counties should adopt technology to enhance efficiency in revenue collection; act on audit reports and hold regular public expenditure review meetings in which expenditures are discussed widely by the county with donors, civil society organizations and citizens.

The foregoing clearly brings out the critical importance of service delivery against challenges of limited financial resources and the need for equitable resource sharing. This said, the studies discussed above present inconclusive evidence on the effect of financial resources on service delivery by counties in Kenya. Informed by the above, this study hypothesized that;

$\boldsymbol{H}_{0:} \quad$ Financial resources do not have a significant effect on the delivery of devolved services in selected counties in Kenya.

\subsection{Theoretical Framework}

This study was anchored on the Resource Based View Theory which postulates that resource management is a key factor in the success of any entity. This theory provides appropriate tools to evaluate the performance of counties on the basis that the success of devolution lies in the counties' ability and capacity to manage their resources effectively so at to improve service delivery, foster economic and social development and improve local revenue generation and collection. Support is offered by Wernerfelt (1984) who argues that the theory provides a framework to enhance efficiency in project and program management, which would enable counties to manage their priorities and expectations in a better way. Finally, the theory gives organizations the tools to assess their 
relationships with their external environments more objectively by providing comprehensive information on the physical and information resource flows involved in the processes.

Furthermore, the theory advocates for the cultivation of both strategic resources and the means of exploiting them efficiently to increase the attainment of organizational goals because it increases a firm's competitiveness organically (Alvarez \& Busenitz 2007). Supporting the reasoning, Stacey (2011) argues that companies need to understand their process flows closely if they are to develop sound plans and allocate their resources in ways that enhance their conversion and reduce wastage. The theory therefore can be appropriately applied to establish how counties generate and employ their financial resources to improve the position of their other resources (human capital, organizational and technological) and as a result improve the attainment of the goals of devolution (Barney \& Hesterly, 2012). It is, therefore, an important tool in innovating for sustainability which is a key element in enhancing the continuity of devolution. Supporting this position, Greene, Brush and Brown (2015) argue that by understanding the resources available to an organization and how they can be leveraged to enhance goal attainment, counties can improve their performance and impact at the same time.

While tangible resources are important to an organization's successful attainment of its set goals, its intangible resources are particularly instrumental in enhancing its performance and ensuring its development of sustainable competitive advantages $(\mathrm{Wu}, 2010)$. This is partly because intangible resources give organizations their personalities and set them apart from others in the space. In this case, intangible resources can play a key role in helping counties to uniquely define and differentiate their development and economic programs in order to increase synergies and encourage trade between them. Having unique structures, processes and products also increases an organization's importance for the benefits of its stakeholders in its ecosystem and also increases its direct business to business transactions making it more cost effective. The Resource Management theory also maintains that organizations are better off developing the capacity of their internal resources because they offer it the best chance of high flexibility. This theory is therefore important in furthering this study's investigations on the effects of devolution on service delivery by allowing it to have a more holistic perspective of the definition of resources and their implications on both performance and impact. The model outlined in figure 1 below explains the Resource Based View (RBV) and emphasizes the key points of it.

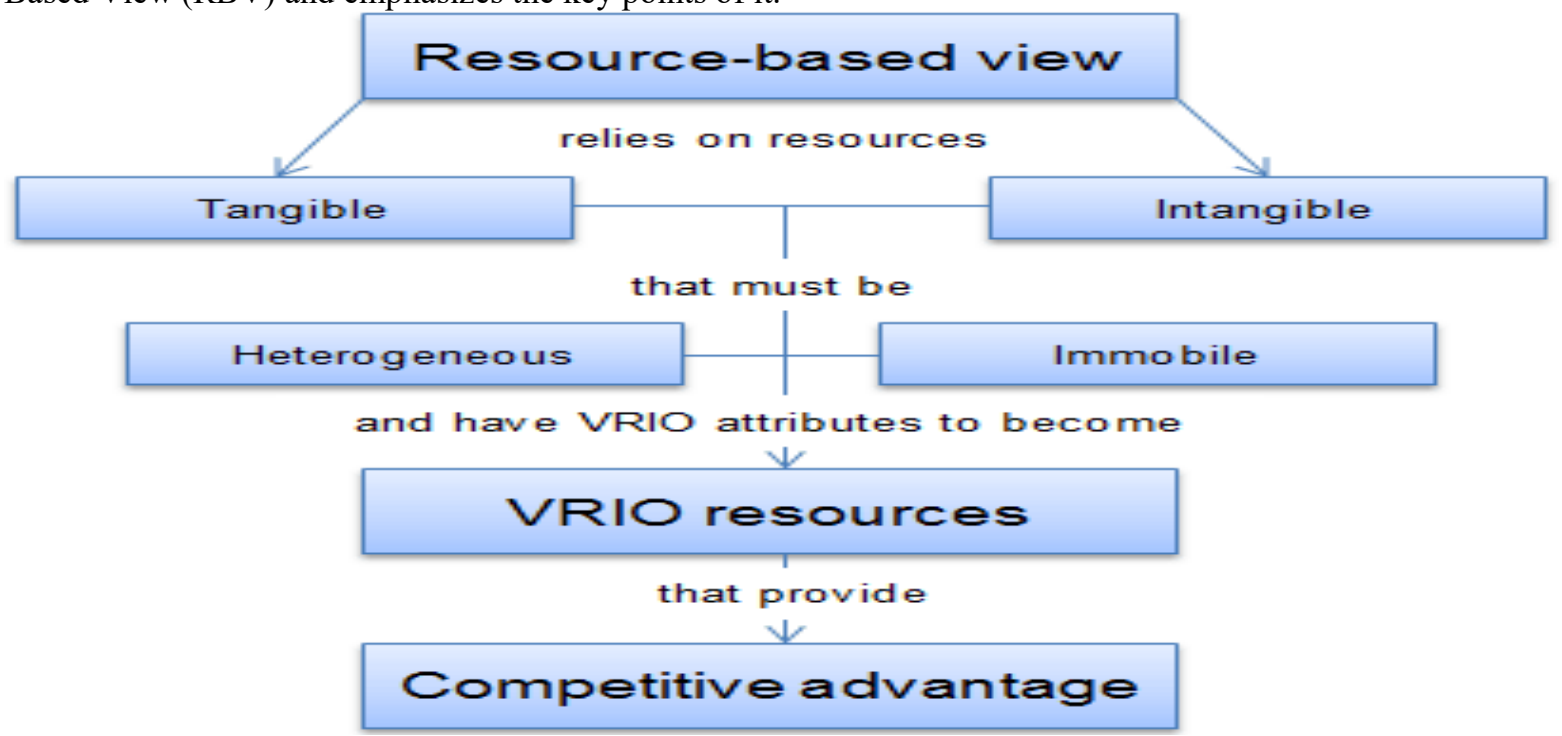

Figure 1 Resource Based Model

Source: (Barney, 1986; Hamel and Prahalad, 1996)

This model diagrammatically presents resources (both tangible and intangible) as key to superior firm performance (service delivery). If a resource exhibits VRIO (valuable, rare costly to imitate and organized to capable value) attributes, the resource enables the firm to gain and sustain competitive advantage which means the organization is able to generate financial resources that enhances it superiority in service delivery compared to other organization

\subsection{Critique of the Existing Literature}

A number of scholars who have carried out empirical studies on devolution have repeatedly called for a better understanding of how devolution relates to effective service delivery. Despite the large number of studies that have been carried out to better understand devolution in Kenya, there still exists some research gaps on the determinants of devolved service delivery outcomes that need further research to help build knowledge in this field. Notably, most researches and literature on devolution have limited applicability on a developing country like Kenya. This situation calls for re-examination of evidence in view of the features that are unique to the country. For instance, 
Kenya's devolution may present a wide variety of factors and dimensions of devolved service that need to be examined in detail. In addition, the impact of some important attributes such as satisfaction, commitment, organizational behavior and attitudes need to be fully examined. Finally, it is also evident that most of the studies reviewed in this paper tested other predictor variables rather than the financial aspect.

A number of studies indicate that financial resources are crucial to devolved service delivery. In this regard, Ghatak (2013) studied demand side factors affecting provision of public services and found that effective public service provision has to be adequately financed and depends critically on the institutional structure. Thus, a county government should have its own system of enforcement mechanisms because unwritten rules in financial resource are likely to hinder or further public service provision. In a related study, Maina (2016) examined the role of public financial management practices on service delivery in counties and found that better budgeting, stakeholder participation practices and better regulatory practices had a positive effect on devolved service delivery in the counties. The researcher further elucidated that revenue mobilization and spending practices and auditing and forensic accounting practices had an insignificant effect on service delivery in the three counties which participated in the study.

\subsection{Material and methods}

The literature reviewed above yields key styled facts that inform the choice of research design for this study: the problem under investigation is not well researched and hence the need to generate a better-tested model. In this regard, this study employed an explanatory research design. As indicated in the objectives that guide this study a positivism research philosophy was used. Consequently, a hypothesis was generated for the purpose of examining the causal-effect relationship of financial resources and delivery of devolved services in selected counties of Kenya. The unit of analysis was all the 47 county governments in Kenya while the unit of enquiry was 35,444 staff from 8 counties in areas that are reachable based on land portrayal. The study adopted cluster sampling technique, wherein participants representing the target population were identified and selected to comprise the sample. Simple random sampling was used to select 384 sampling elements from employee lists maintained by human resources departments in the selected counties.

Questionnaires with both close and open-ended questions were administered on the sampling elements to collect data. The closed-end questions required every respondent to rate every proclamation that depicted a given variable using a Likert scale from 1-5 whereby $1=$ Strongly Disagree, $2=$ Disagree, 3=Neutral, 4=Agree, and $5=$ Strongly Agree. The open-ended inquiries were incorporated to obtain further data from the respondents that was not captured in the closed-ended questions. This primary data was supplemented by secondary data from published reports and records in the Ministry of Devolution and Arid and Semi-Arid Lands which oversees county governments.

In line with the research design, a pilot test was carried out to empower the legitimacy and improve the quality of the exploration instrument (Copper \& Schilder, 2006). To improve on reliability of the study, respondents who had been interviewed during the pilot test were excluded from the final investigation. All the items in the variables were noted to be above the minimum 0.7 which is an acceptable rating on the Cronbach's alpha. In addition, construct validity, convergent construct and discriminant construct validity were established using factor and correlation analysis. Table 1 below shows that the factor loadings results were above 0.5 which implies that all the factors could be retained for further analysis. Besides, AVE of 0.633 indicated that $63.3 \%$ of variance was captured by the financial resources construct in relation to the amount of variance due to the measurement error. In summary, the first factor accounted for $28.64 \%$ of the total variance, the second factor accounted for $14.32 \%$ and the third factor $13.02 \%$ of the total variance leading to a cumulative $55.98 \%$ of variance accounted for. The Kaiser-MeyerOlkin Measure value (0.766) was above 0.5 hence acceptable, thus the response of $90 \%$ was adequate to subject the data for factor analysis. Also, the Bartlett's Test was significant. This indicated that all the factors were valid and hence retained for further analysis in the study. Further, the high factor loading scores means that financial resources is accounted for by all the items considered.

As recommended by Kaiser (1960) as well as Yong and Pearce (2013) Eigen value of greater than 1 was retained for further analysis. In this study the Eigen values displayed in table 1 indicated a value of 2.864 which is greater than 1. Following the findings of Eigen value higher than 1, all the nine constructs as shown in table 1 below were identified to be single factor. This factor accounted for $55.979 \%$ of the total variance. 
Table 1: Factor Analysis for Financial resources

\begin{tabular}{|c|c|c|c|}
\hline & 1 & 2 & 3 \\
\hline $\begin{array}{l}\text { The county government allocate finances to the projects and services in county } \\
\text { in time } \\
\text { The county government officials are able to account the amount spent in every } \\
\text { financial year }\end{array}$ & 0.703 & & \\
\hline During budget, the major consideration in allocation of money is priorities & 0.641 & & \\
\hline $\begin{array}{l}\text { The county government carry out internal audit of the its financial expenditures } \\
\text { The county government is able to implement both internal and external auditors } \\
\text { suggestions }\end{array}$ & 0.687 & & \\
\hline The county government account is in deficit & \multicolumn{3}{|c|}{0.851} \\
\hline $\begin{array}{l}\text { The county government makes transitional budget } \\
\text { The amount of money received from the national government is enough to run } \\
\text { the affairs of the county } \\
\text { The county government revenue is enough to support county government } \\
\text { services }\end{array}$ & & 0.659 & 0.811 \\
\hline Total Variance Explained Rotation Sums of Squared Loadings & & & \\
\hline Initial Eigenvalues & 2.864 & 1.432 & 1.302 \\
\hline$\%$ of Variance & 28.64 & 14.32 & 13.019 \\
\hline Cumulative $\%$ & 28.64 & 42.96 & 55.979 \\
\hline AVE & 0.633 & & \\
\hline
\end{tabular}

KMO and Bartlett's Test

Kaiser-Meyer-Olkin Measure of Sampling Adequacy.

0.766

Bartlett's Test of SphericityApprox. Chi-Square

Df

Sig.

Cronbach's Alpha

Extraction Method: Principal Component Analysis.

Rotation Method: Varimax with Kaiser Normalization.

Quantitative methods were employed to analyse the data collected using both descriptive and inferential statistics. The Likert scale data which was measured using an ordinal scale was transformed to a ratio scale that employed the scores assigned in the research ranging from 1 to 5 . This transformation enabled the generation of descriptive and inferential statistics to support quantitative analysis. This operation is in line with Chen and Wang (2014) who suggested that one method of assigning a score to ordinal categorical data is to assign a score subjectively.

Based on the foregoing, descriptive statistics such as means, standard deviations, skewness and kurtosis, were generated to explain the variables. With respect to inferential statistics, Pearson correlation and simple linear regression analysis were conducted to establish the strength and direction of the relationship between the independent and dependent variables. In addition, the validity of the simple regression models was tested using ANOVA, F-distribution and t-test. According to Mugenda and Mugenda (2003), ANOVA can be used to determine whether there are significant differences between two or more groups or samples at a selected probability level. To test the significance of regression coefficient, t-test was performed where a significance level of 0.05 was adopted to interpret the $p$ value obtained in the analysis. Consequently, the null hypothesis was rejected if the $p$ value was less than 0.05 and not rejected if the $p$ value was greater than 0.05 . Simple linear regression model was utilized on the hypothesis.

The simple regression model was;

$Y=\beta_{0}+\beta_{1} X+\varepsilon$

Where:

$\mathrm{Y}=$ Devolved services delivery

$\mathrm{X}=$ Financial resources

$\varepsilon=$ Error term

$\beta_{0}=$ Constant $(\mathrm{Y}$ intercept $)$ 
$\beta_{1}=$ Is the regression coefficient of $\mathrm{X}$

\subsection{Findings and Discussion}

This section presents results of data analysis and hypotheses testing. The purpose of this study was to examine the effect of financial resources on the delivery of devolved services in selected counties in Kenya.

\subsection{Descriptive Results}

Financial resources are usually regarded as important inputs in county processes where the attainment of effective devolved service delivery is an overarching goal. This study therefore sought to find whether financial resources have any effect on the delivery of devolved services. The simple mean score of the nine constructs that that operationalized financial resources in table 1 above was the independent variable in this study. Table 2 below illustrates the results.

Table 2: Descriptive Statistics for the Study

\begin{tabular}{lccccrrr}
\hline & N & Min & Max & Mean & Std. Deviation & Skewness & \multicolumn{1}{c}{ Kurtosis } \\
\hline Financial resources & 346 & 1.000 & 4.800 & 3.256 & 0.610 & -0.283 & 0.620 \\
Service delivery & 346 & 1.000 & 4.890 & 3.270 & 0.867 & -0.383 & -0.383 \\
\hline
\end{tabular}

The findings on the role of financial resources yielded a mean of 3.26 (out of a maximum of 5), standard deviation of 0.61 and a skewness of -0.28 . The mean which implies that respondents were on average neutral, although tending towards agreeing, on the importance of financial resources to service delivery, suggests the existence of gaps in terms of the provision and use of financial resources at the county level. To build on the results, it can be affirmed that the manner in which financial resources are dispersed may either have a positive or negative effect on service delivery. This is supported by findings in a study by Tsofa (2017) in Kilifi County government of Kenya who reported that the rapid transfer of human and financial resources for health management functions before the counties had enough capacity to undertake these functions led to poor service delivery. The timing and capacity to perform devolved functions are also important in enhancing devolved service delivery.

Table 2 above further presents the descriptive statistics pertaining to the results on devolved service delivery. The findings on devolved service delivery are an aggregate mean of 3.27, standard deviation of 0.87 and a skewness of -0.38 . It is notable that this distribution is closely aligned to the one of financial resources especially for the mean score. However, a larger standard deviation and skewness indicates a wider variation in respondents' views regarding the quality of devolved service delivery.

Finally, with regard to both financial resources and service delivery, the values of skewness and kurtosis were within the range of \pm 1.98 indicating the means do not violate the assumption of normality. This enables inferential analysis that require normal distribution.

\subsection{Hypothesis testing}

There was a moderately strong positive relationship between financial resources and service delivery $(r=0.606$, $p$-value $<.01$ ) which gave ground for performing regression analysis. This was informed by the fact that regression is one of the pertinent and commonly used statistical methods in research as a platform for examining causal-effect relationships among variables of interest in a study. One of its advantages is the ease in quantifying the effect of changes in the response variable as a result of changes in predictor variables (Darlington \& Hayes, 2016; Mills \& Tosic, 2011; Hair et al., 2010). Therefore, regression analysis was performed to test the model fit and to establish the predictive power of the model in the response variable.

$\mathbf{H}_{0}$ : Financial resources do not have a significant effect on the delivery of devolved services in selected counties in Kenya.

This hypothesis stated that financial resources had no significant effect on the delivery of devolved services in the selected counties in Kenya. However, findings in this study as displayed in table 3 below showed that financial resources had coefficients of estimate which was significant basing on $\beta_{0}=0.467$ ( $p$-value $=0.021$ for the $Y$ intercept; and $\beta_{1}=0.861$ (p-value $=0.000$ for the coefficient of the independent variable (financial resources). Both p-values are below $\alpha(=0.05)$ and are significant and therefore should be retained in the equation. The null hypothesis was rejected on the basis of the significant $\beta_{1}$. This indicated that for each unit increase in financial resources, there was 0.861 units increase in the level of service delivery. Furthermore, the effect of financial resources was stated by the t-test value $=14.120$ which implied that the standard error associated with the parameter was less than the effect of the parameter. Also the R Square score indicated that financial resources explained $36.7 \%$ variation in of service delivery. Further, the coefficient of determination was significant as evidenced by a $\mathrm{F}$ ratio of 199.379 with $\mathrm{p}$ value $0.000<0.05$ (level of significance). 
Table 2: Effect of Financial Resources on the delivery of devolved services

\begin{tabular}{|c|c|c|c|c|c|}
\hline & \multicolumn{2}{|c|}{ Unstandardized Coefficients } & \multicolumn{3}{|c|}{ Standardized Coefficients } \\
\hline & B & Std. Error & Beta & $\mathbf{T}$ & Sig. \\
\hline (Constant) & 0.467 & 0.202 & & 2.314 & 0.021 \\
\hline Financial resources & 0.861 & 0.061 & 0.606 & 14.120 & 0.000 \\
\hline \multicolumn{6}{|l|}{ Summary Statistics } \\
\hline$R$ & \multicolumn{2}{|c|}{0.606} & & & \\
\hline$R$ Square & \multicolumn{2}{|c|}{0.367} & & & \\
\hline Adjusted R Square & \multicolumn{2}{|c|}{0.365} & & & \\
\hline ANOVA (F stat) & \multicolumn{2}{|c|}{199.379} & & & \\
\hline$A N O V A(F$ prob) & \multicolumn{2}{|c|}{0.000} & & & \\
\hline Correction results (r) & \multicolumn{2}{|c|}{$606 * *$} & & & \\
\hline \multicolumn{6}{|c|}{ Assumption of regression model } \\
\hline \multirow[t]{4}{*}{ Normality } & \multicolumn{2}{|c|}{ Kolmogorov-Smirnov } & 0.213 & & \\
\hline & \multicolumn{2}{|l|}{ Sig. } & $200 *$ & & \\
\hline & \multicolumn{2}{|c|}{ Shapiro-Wilk } & 0.802 & & \\
\hline & \multicolumn{2}{|l|}{ Sig. } & 0.337 & & \\
\hline \multirow[t]{2}{*}{ Heteroscedasticity Test } & \multicolumn{2}{|c|}{ Levene Statistic } & 0.911 & & \\
\hline & \multicolumn{2}{|l|}{ Sig. } & 0.301 & & \\
\hline \multirow[t]{2}{*}{ Collinearity Statistics } & \multicolumn{2}{|l|}{ Tolerance } & 0.575 & & \\
\hline & \multicolumn{2}{|l|}{ VIF } & 1.740 & & \\
\hline
\end{tabular}

a Dependent Variable: Devolved Service Delivery

Findings from the regression analysis revealed that financial resources positively and significantly contribute to the delivery of devolved services in the selected counties in Kenya. Other findings from this study were that county governments are yet to make sufficient concerted efforts in the allocation of finances to projects and services in a timely manner. In addition, county officials have a challenge accounting for the amount of money spent in every financial year. Further, county government revenues are not sufficient to support county government services. Despite the above county governments are able to make the yearly budget.

Further, it is undefined if the county government account is in deficit. This is also the case with the county making transitional budget. Also, the amount of money received from the national government appears not enough to run the affairs of the county. Moreover, it was noted that priorities are the major consideration when allocating money during budgeting. On the positive angle, the study found that county governments carrys out internal audit of their financial expenditures and strive to enhance accountabilityby implementing both internal and external auditors' suggestions.

\subsection{Conclusion and Recommendations}

The main objective of this study was to assess the effect of financial resources on the delivery of devolved services in selected counties in Kenya. The study concludes that financial resources do influence delivery of devolved services in Kenya, Firstly, results from regression analysis revealed that there is a statistically significant positive relationship between financial resources and county delivery of devolved services. The model results indicate that financial service account for about one third of the variation of delivery of county services. However, the model also suggests that in the absence of financial services, counties can still achieve about $10 \%$ delivery of devolved services. Intuitively, having financial resources enables counties to allocate resources where they are needed and ultimately leads to county socio-economic development. In the context of the study, the deployment of financial resources contributes to improved ease of doing business and ability to provision of services: these two are important anchors for a thriving private sector.

Financial resources are the lifeblood of projects and programmes at the county government level. It is however a delicate balance since the resources may be in place but the mechanisms to deploy them may be non-existent. The implication is that, unless provision is based on effective delivery mechanisms, resources will be wasted. In certain instances, the county governments lack the capacity to generate sufficient revenue to spur service delivery thereby necessitating further revenue allocation from the national government. From a national policy perspective, the challenge however is balancing the allocations between these two levels of governments and the predominant issue of the efficacy and of management of resources. This suggests the existence of gaps that need to be addressed for financial resources to improve devolve service delivery. 
Since financial resources have a positive and significant effect on devolved service delivery, there is need for counties to device appropriate procedures to ensure high revenue collections. A case can also be made for increased advocacy for a review of national allocation policies in favour of increasing the tranche available to counties. Cognisant of the challenge of limited resources it is important to ensure that a good balance is made in the allocations of resources between the national and county government where the ultimate goal is enhanced service delivery and faster socio-economic development.

To widen the financial resources envelop, the study recommends that county governments should make arrangements to facilitate the disbursement of extra special funds. Also, to increase efficiency in the utilisation of financial resources, it is recommended that county governments undertake internal audits of its financial expenditures and implement both internal and external auditors' recommendations. This study further recommends that county governments should take initiatives towards generating an annual surplus of revenues over expenditures by exploiting diversified sources of revenue.

One direction of future research would be to replicate this study in other counties not covered in the study. Furthermore, in terms of methodology, scholars can conduct a longitudinal study as well as appreciate both the quantitative and qualitative aspects of research. Using the nine constructs that were identified to operationalize financial resources, a multiple regression model can be applied to determine the relative importance of each. The above said, , this paper has contributed knowledge that is needed for this kind of research.

\section{REFERENCES}

Alvarez, S.A. \& Busenitz, L.W. (2007). The entrepreneurship of resource-based theory. In Entrepreneurship: Concepts, Theory and Perspective. 207-227.

Barasa, E. (2017). Recentralization within decentralization: County hospital autonomy under devolution in Kenya. PLOS journal, 12(8).

Barney, J., \& Hesterly, W. (2012). Strategic management and competitive advantage: Concepts and cases (4th ed.). Upper Saddle River, NJ: Prentice Hall.

Bigambo, J. (2013). Devolution in Kenya \& decentralization in Africa .Benchmarking. Inter thought consulting, connecting ideas beyond borders.

Cooper, D. R., \& Schindler, P. S. (2006), “Business Research Methods” (9th edition), USA: McGraw-Hill

Ghotak, A. (2013). Demand side factors affecting provision of public services, Research Journal of Social Science \& Management, ISSN:2251-157, Volume 03, No. 01.

Greene, P., Brush, C., \& Brown, T. (2015). Resources in small firms: An exploratory study. Journal of Small Business Strategy, 8, 25-40. Retrieved from http://www.jsbs.org/.

Kauzya, J.M., 2007. Political Decentralization in Africa: Experiences of Uganda, Rwanda and South Africa. In: Cheema, G.S. \& Rondinelli, D.A., eds. 2007. Decentralizing Governance: Emerging Concepts and Practices. Washington: Brookings Institution Press.75-91.

Maina, J. (2017). The role of public financial management practices on service delivery in selected counties: perception of members of county assembly. Unpublished thesis of KCA.

Mugenda, O. M., \& Mugenda, A. G. (2003). Research Methods: Quantitative and Qualitative Approaches. Nairobi: African Centre for Technology Studies Press.

Musya, J., \& Orodho, J. A. (2014). Performance Contracts and Service Delivery: What Is The Level of Preparedness of School Managers in Management of Secondary Schools in Makueni County, Kenya. Research on Humanities and Social Sciences, 4(21), 2224-5766.

Pollitt, C. \& Bouckaert, G. (2011). Public management reform: a comparative analysis: New Public management, Governance and the Neo-Weberian State. Oxford: Oxford University Press.

Stacey, R., (2011). Strategic management and organizational dynamics: The challenge of complexity. (6th ed.) Boston, MA: Pearson Education Company.

Tsofa, B. (2017). Devolution and its effects on health workforce and commodities management - early implementation experiences in Kilifi County, Kenya. Int J Equity Health.

Wernerfelt, B. (1984). The Resource-Based View of the Firm: Ten Years After. Strategic Management Journal, $16,171-174$.

World Bank (2012). Devolution without disruption, Pathways to a successful new Kenya, Poverty Reduction and Economic Management Unit Africa Region.

World Bank (2013). "Kenya Economic Update: Time to shift gears. Accelerating growth and poverty reduction in the new Kenya. "Nairobi, World Bank.

World Bank (2015).Kenya devolution. Building Public Participation in Kenya's Devolved Government

Wu, L.Y. (2010). Applicability of the resource-based and dynamic-capability views under environmental volatility. Journal of Business Research, 63, 27-31. 